\title{
UMBILICAL CORD BLOOD HEMATOLOGY IN RELATION WITH MATERNAL ANEMIA: A PRELIMINARY STUDY
}

\author{
RUMI DEBBARMA ${ }^{1 *}$, PANKAJ ${ }^{2}$, M. ANITA DEVI ${ }^{3}$ \\ ${ }^{1}$ Department of Maulana Azad Medical College, New Delhi, India. ${ }^{2}$ Department of Indraprastha Apollo Hospital, Jasola, New Delhi, India. \\ ${ }^{3}$ Department of Regional Institute of Medical Sciences, Imphal, Manipur, India. Email: rumidb15@gmail.com
}

Received: 19 April 2018, Revised and Accepted: 26 June 2018

\section{ABSTRACT}

Objectives: The aim of this study was to observe any umbilical cord blood hematological changes in relation to maternal anemia.

Methods: We conducted a cross-sectional study on 220 neonates and their mothers from August 1, 2015, to July 31, 2016, in collaboration with the Department of Obstetrics and Gynaecology, Regional Institute of Medical Sciences, Imphal, India. Immediately after vaginal delivery of baby, umbilical cord was clamped and blood was collected in EDTA vials and analyzed using automated hematoanalyzer

Results: Neonates of non-anemic mothers had significantly higher level of hemoglobin concentration than neonates of anemic mothers. Total leukocyte count (TLC) was slightly higher in neonates of non-anemic mothers as compared to neonates of anemic mothers. Platelet count was slightly higher in neonates of anemic mothers as compared to non-anemic mothers, but platelet crit, mean platelet volume, and platelet cell distribution width were slightly higher in neonates of non-anemic mothers than neonates anemic mothers.

Conclusions: It was a preliminary study. A similar type of the study must be conducted in future to comprehend the effect of various other factors affecting delivery such as maternal anemia, diet, and environment on blood parameters of newborns.

Keywords: Cord blood, Plateletcrit, Platelet cell distribution width, Maternal anemia.

(C) 2018 The Authors. Published by Innovare Academic Sciences Pvt Ltd. This is an open access article under the CC BY license (http://creativecommons. org/licenses/by/4. 0/) DOI: http://dx.doi.org/10.22159/ajpcr.2018.v11i10.26789

\section{INTRODUCTION}

Umbilical cord blood and its components haves very important part of neonatal hematology nowa a days [1]. To diagnose any kind of neonatal diseases related to hematology, we frequently use cord blood cell and indices as because cord blood analysis gives an important information about the condition of health both of neonates and pregnant mothers. Red blood cell (RBC) and red cell indices are used in the diagnosis and follow-up of various neonatal diseases and infant anemias. White blood cell (WBC) is useful in the assessment of fetal infection and sepsis, whereas cord blood platelet count is important for the assessment of fetal thrombocytopenia and any hemostatic condition of neonates [2-4].

Umbilical cord blood stem cells have a high level of division and are multipotent. The only important source of nutrients for intrauterine growing fetus is maternal blood and fetal "parasitism" is seen, means irrespective of maternal iron level transport of iron from mother to fetus occurs independently, which can lead to deficiency in the mother, mainly iron deficiency anemia during pregnancy.

Iron deficiency anemia is a most common nutritional disorder and serious public health concern in developing countries, and maternal iron deficiency anemia increases the incidence of maternal mortality and morbidity as well it also increases the incidence of fetal growth retardation, premature delivery, and neurodevelopment of the fetus $[6,7]$.

Previous some studies have shown that red blood cell count of term newborns was significantly higher compared to adult values with hemoglobin $(\mathrm{Hb})$ levels ranging from 11.2 to $26.6 \mathrm{~g} / 100 \mathrm{ml}$ [10]. Another study which was conducted on 600 healthy term newborns shows that PCV was higher when collected and analyzed $24 \mathrm{~h}$ after the birth [11].
Maternal anemia classification

The Indian Council of Medical Research has classified anemia during pregnancy according to their hemoglobin levels into mild, moderate, and severe.

\begin{tabular}{ll}
\hline Severity of anemia & Hemoglobin in $\mathbf{g} / \mathbf{d l}$ \\
\hline Mild & $10-10.9$ \\
Moderate & $9.9-7$ \\
Severe & $6.9-4$ \\
Very severe & $<4$ \\
\hline
\end{tabular}

\section{METHODS}

This was a observational cross-sectional study conducted at the Department of Physiology in collaboration with the Department of Obstetrics and Gynaecology, Regional Institute of Medical Sciences (RIMS), Imphal, India.

A detailed history was taken from mothers before delivery regarding their parity, age, gravida, and socioeconomic status. All mothers were screened for HIV when they attend antenatal clinic for the first time and repeated at last trimester, and those tested negative were included in this study. Before the collection of blood sample, "informed" verbal consent was obtained from all mothers.

\section{Subjects}

A total of 220 health pregnant women who delivered their babies during August 1, 2014-July 31, 2016 (2 years), at the Department of Obstetrics and Gynaecology, RIMS, Imphal, India, were taken as subjects.

\section{Inclusion criteria}

For mothers

Booked cases who received antenatal care at RIMS, normal vaginal delivery, $\mathrm{Hb}>10 \mathrm{~g} / \mathrm{dl}$, primi/multiparity, and mothers' age group between 18 and 45 years were included in the study. 


\section{For neonates}

Neonates with full-term gestation (37-42 weeks), weighing 2.5-4 $\mathrm{kg}$ babies delivered normal vaginally and irrespective of parity, were included.

\section{Exclusion criteria}

\section{For mothers}

Pregnant mothers who had complaints of antepartum hemorrhage, eclampsia, history of diabetes, any cardiovascular endocrine, metabolic, or endocrine diseases, lung diseases, hematological diseases (e.g., sickle cell disease and thalassemia), drug/alcohol abuse, having HIV, hepatitis B and C infections, and malaria were excluded from the study.

\section{For neonates}

Neonates who were born with any congenital anomalies or any chromosomal abnormality, hydrops fetalis, birth asphyxia, abnormal partogram, perinatal blood loss, and any pathological jaundice within $24 \mathrm{~h}$ of birth were excluded.

\section{Sample collection}

Immediately after delivery of the baby by clamping and cutting the cord, around $5 \mathrm{ml}$ of umbilical cord blood samples were collected. Around $2 \mathrm{ml}$ of venous blood samples from antecubital fossa of the mothers were also collected inside the labor room before delivery of the babies and in EDTA vials.

\section{Hematological analysis in laboratory}

Blood count for both umbilical cord blood samples and maternal blood samples was done as soon as possible (maximum 2-3 h) after collection of samples using automated hematoanalyzer at the Hematology Department of Physiology, RIMS, Imphal, India.

\section{Instrument: SAMSUNG LABGED HCIO, MODEL: IVD-CIOA}

\section{Statistical and data analysis}

Data analysis was performed using SPSS version 21. Mean, median, mode, and standard deviation (SD) were calculated. Student's t-test was used to compare parameters between two groups, and $p<0.05$ was taken as statistically significant

\section{Ethical clearance}

Clearance from the Institutional Ethical Committee was taken before conducting the study and informed written consent was obtained from all mothers who have participated in this study before collection of blood. Confidentially was maintained.

\section{RESULTS}

A total of 220 maternal and umbilical cord blood were analyzed, and of 220 neonates, 117 (53\%) were males and 103 (47\%) were females.

Of 220 mothers, 161 (73\%) mothers were non-anemic having $\mathrm{Hb}$ $>11 \mathrm{~g} / \mathrm{dl}$ and 59 (27\%) were included in anemic criteria having hemoglobin level $<11 \mathrm{~g} / \mathrm{dl}$

Of 220 mothers, 161 (73\%) mothers had normal hemoglobin concentration and 59 (27\%) had low hemoglobin concentration, of which 46 had mild, 13 moderate, and no one had severe anemia.

Table 1 shows the mean and SD and correlation between the neonatal cord blood of non-anemic and anemic mothers. $\mathrm{Hb}, \mathrm{RBC}$, hematocrit (HCT), mean cell volume (MCV), mean corpuscular hemoglobin concentration (MCHC), and mean corpuscular hemoglobin ( $\mathrm{MCH}$ ) were found to be higher in neonates of non-anemic mothers when compared to neonates of anemic mothers, but only $\mathrm{Hb}$ was significantly higher $(p=0.029)$. RDWc was slightly higher in neonatal cord blood of anemic mothers as compared to non-anemic mothers $(\mathrm{p}=0.415)$.

Table 2 shows that total leukocyte count was slightly higher in newborns of non-anemic mothers as compared to newborns of anemic mothers.

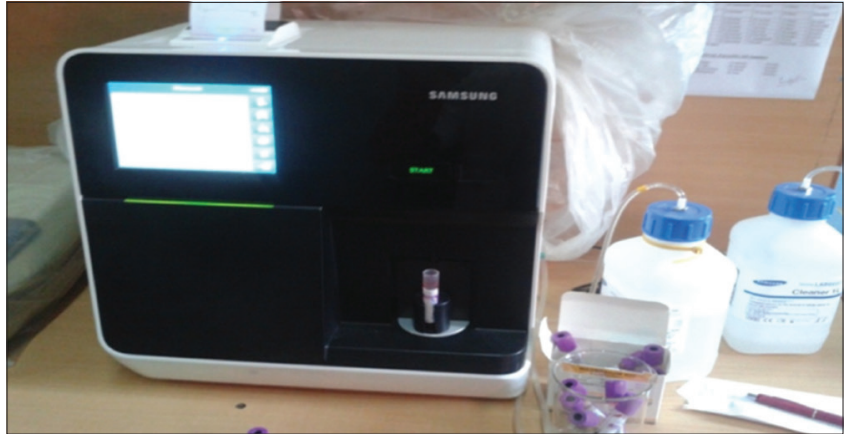

Fig. 1: Hematoanalyzer (in the Physiology Department, Hematology Laboratory, RIMS, Imphal)

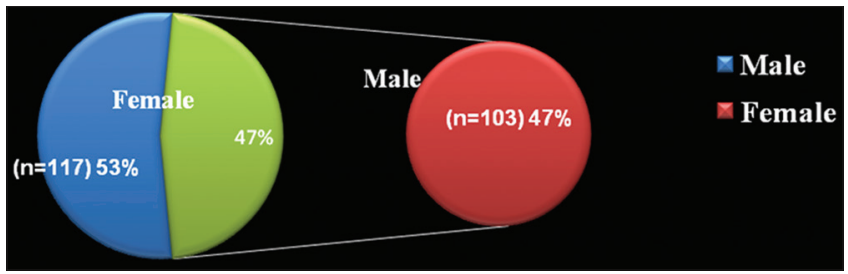

Fig. 2: Gender-wise distribution of newborns $(n=220)$

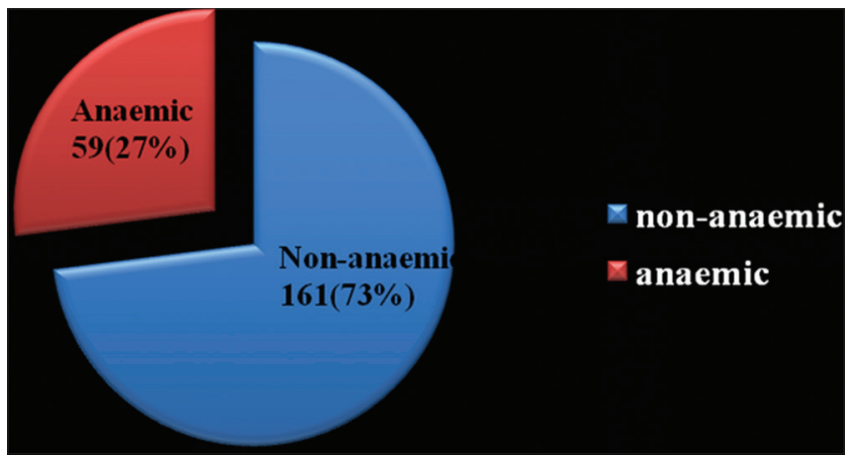

Fig. 3: Pie diagram showing the percentage of anemic (27\%) and non-anemic mothers (73\%)

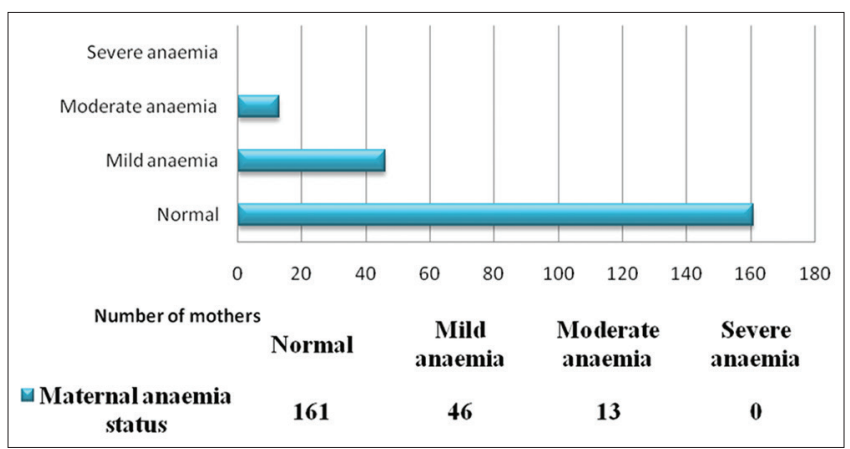

Figure 4: Bar diagram showing maternal anemia status

Platelet count was slightly higher in neonates of anemic mothers as compared to non-anemic mothers. Plateletcrit (PCT), mean platelet volume (MPV), and PDWc values were higher in neonates of nonanemic mothers as compared to anemic mothers but not significant statistically.

\section{DISCUSSION}

Anemia during pregnancy has various undesirable effects on maternal health and outcomes. During pregnancy, usually lower values of 
Table 1: Relation of maternal anemia status with red cell values of cord blood $\left({ }^{*} \mathbf{p}<0.05\right)$

\begin{tabular}{llll}
\hline Parameters & Non-anemic $(\mathbf{n = 1 6 1 )}$ & Anemic $(\mathbf{n = 5 9 )}$ & p value \\
\hline Hb $(\mathrm{g} / \mathrm{dl})$ & $17.88 \pm 1.79$ & $15.22 \pm 2.02$ & $0.028^{*}$ \\
RBC $(\mathrm{m} / \mu \mathrm{l})$ & $4.75 \pm 0.61$ & $4.72 \pm 0.78$ & 0.790 \\
$\mathrm{HCT}(\%)$ & $48.55 \pm 6.27$ & $46.57 \pm 7.79$ & 0.083 \\
MCV (fl) & $102.66 \pm 7.26$ & $100.44 \pm 7.99$ & 0.065 \\
MCHC (g/l) & $325.62 \pm 21.69$ & $325.29 \pm 29.89$ & 0.755 \\
MCH (pg) & $33.58 \pm 2.68$ & $32.64 \pm 3.69$ & 0.077 \\
RDWc (\%) & $16.24 \pm 1.37$ & $16.38 \pm 1.02$ & 0.415 \\
\hline
\end{tabular}

MCV: Mean cell volume, MCH: Mean corpuscular hemoglobin, RBC: Red blood cell, HCT: Hematocrit, Hb: Hemoglobin, MCHC: Mean corpuscular hemoglobin concentration

Table 2: Umbilical cord blood TLC and platelet parameters in relation with maternal anemia

\begin{tabular}{llll}
\hline Parameters & $\begin{array}{l}\text { Non-anemic } \\
(\mathbf{n = 1 6 1 )}\end{array}$ & $\begin{array}{l}\text { Anemic } \\
(\mathbf{n = 5 9 )}\end{array}$ & p value \\
\hline TLC $(1000 / \mu \mathrm{l})$ & $14.05 \pm 6.29$ & $13.47 \pm 4.79$ & 0.468 \\
Platelet count $(1000 / \mu \mathrm{l})$ & $235.70 \pm 59.28$ & $242.03 \pm 53.77$ & 0.454 \\
PCT $(\%)$ & $0.19 \pm 0.16$ & $0.17 \pm 0.09$ & 0.247 \\
MPV (fl) & $8.94 \pm 1.83$ & $8.78 \pm 1.98$ & 0.589 \\
PDWc (\%) & $37.23 \pm 2.80$ & $36.44 \pm 3.06$ & 0.086 \\
\hline
\end{tabular}

TLC: Total leukocyte count, MPV: Mean platelet volume, PCT: Plateletcrit

maternal blood hemoglobin and hematocrit are observed, which may be due to the expansion of blood plasma volume which leads to hemodilution during pregnancy. Physiological changes during pregnancy lead to modification of chemical composition of blood, hematopoietic micronutrients transfer amplification, and as defense mechanism against oxidative stress during pregnancy, few of this micronutrients are utilized more, which may lead to low hematological values during pregnancy [12].

Few studies had considered that measurement of red cell indices and pigments would be more helpful for pregnant women and their newborns because the volumetric changes in cardiovascular system occur at this time.

Normally, hematocrit level is found high in $1^{\text {st }}$ week of life because of increased number and size of red blood cells in cord blood [13].

In the present study, the effects of anemia during pregnancy on the newborn by assessing the cord blood hematology were taken. Maternal anemia and umbilical cord blood hemoglobin concentration show a linear relationship, which was similar to the study done by Adem and Babiker [9].

In our study, we have found that umbilical cord blood hemoglobin concentration in newborns of non-anemic mothers was significantly higher $(\mathrm{p}<0.029)$ than newborns of anemic mothers. The cause could be probably compromise in fetal iron during pregnancy, and it has been reported that maternal stored iron influences fetal iron store and there is a limit for fetus to accumulate iron at very low or absent maternal iron store. Red cell indices (HCT, MCV, and MCHC) were slightly higher in newborns of non-anemic mothers than anemic mothers which may be due to poor nutritional status and less iron store during pregnancy.

Umbilical cord blood total leukocyte count was found to be slightly higher side in newborns of mothers who were non-anemic as compared to newborns of anemic mothers but not significant statistically. Umbilical cord blood platelet count, PCT, MPV, and PDWc values show no significant difference between two groups.

\section{CONCLUSION}

It was a preliminary study. This study was conducted as because there were no data available for umbilical cord blood hematology in the northeastern region. A similar type of the study must be conducted to fully comprehend the effect of various other factors affecting delivery such as maternal anemia, diet, and environment on blood parameters of newborns.

\section{AUTHOR'S CONTRIBUTIONS}

All the authors were contributed equally to this work.

\section{CONFLICTS OF INTEREST}

The authors declared that they have no conflicts of interest.

\section{REFERENCES}

1. Elgari MM, Waggiallah HA. Assessment of hematological parameters of neonatal cord blood in anemic and non-anemic mothers. J Clin Exp Res 2013;1:22-5

2. Qaiser DH, Sandila MP, Omair A, Ghori GM. Correlation of routine haematological parameters between normal maternal blood and the cord blood of healthy newborns in selected hospitals of Karachi. J Coll Physicians Surg Pak 2013;23:128-31.

3. Mamoury GH, Hamedy AB, Akhlaghi F. Cord haemoglobin in newborn in correlation with maternal haemoglobin in Northeastern Iran. Indian J Manag Sci 2003;28:166-8.

4. Singla PN, Chand S. Effect of maternal anaemia on the placenta and the newborn infant. Acta Paediatr 2008;67:645-8.

5. Hall JM, Lingenfelter P, Adam SL, Lasser D, Hansen JA, Bean MA. Detection of maternal cells in human umbilical cord blood using fluorescence in situ hypertension. Blood 1995;86:2829-32.

6. Bhanushali MM, Shirode RA, Joshi MY, Kadam JV. An intervention on iron deficiency anemia and change in dietary behaviour among adolescent girls. Int J Pharm Pharm Sci (IJPPS) 2011;3:40-2.

7. Hashem F, Nasr M, Ahmed Y. Preparation and evaluation of iron oxide nanoparticles for treatment of iron dficiency anemia. Int J Pharm Pharm Sci 2018;10:142-6

8. Rao S, Srikanth S. Prevelence of anemia in first trimester of pregnancy in rural papulation of Krishna district in Andhra Pradesh. Sch J App Med Sci 2013;1:570-4

9. Adem I, Babiker S. Low body mass index, anaemia and poor perinatal outcome in a rural hospital in eastern Sudan. J Trop Pediatr 2008;54:202-4.

10. Andrews BF, Willet GP. Fetal hemoglobin and packed cell volume concentration in the Newborn. Am J Obstet Gynecol 1965;16:58-88.

11. Virginia DB, Lula OL. Neonatal polycythemia and hyperviscosity. Pead Clin Amer 1982;???:1137-48.

12. Nneli RO, Amadi SC, Nwafia WC. Certain red blood cell indices of maternal and umbilical cord blood in Owerri, Nigeria: A preliminary report. Ann Med Health Sci Res 2011;1:1-8.

13. Chang LL, Chau K, Yong YC, Sivasamboo R. Some haematological differences between the blood of mothers and their newborn infants. Sing Med J 1972;13:280-3 